\title{
Using intervention mapping to deconstruct cognitive work hardening: a return-to-work intervention for people with depression
}

\author{
Adeena Wisenthal ${ }^{*}$ and Terry Krupa
}

\begin{abstract}
Background: Mental health related work disability leaves are increasing at alarming rates with depression emerging as the most common mental disorder in the workforce. Treatments are available to alleviate depressive symptoms and associated functional impacts; however, they are not specifically aimed at preparing people to return to work. Cognitive work hardening (CWH) is a novel intervention that addresses this gap in the health care system. This paper presents a theoretical analysis of the components and underlying mechanisms of $\mathrm{CWH}$ using Intervention Mapping (IM) as a tool to deconstruct its elements.
\end{abstract}

Methods: The cognitive sequelae of depression and their relevance to return-to-work (RTW) are examined together with interpersonal skills and other work-related competencies that affect work ability. IM, a tool typically used to create programs, is used to deconstruct an existing program, namely $\mathrm{CWH}$, into its component parts and link them to theories and models in the literature.

Results: CWH has been deconstructed into intervention elements which are linked to program performance objectives through underlying theoretical models. In this way, linkages are made between tools and materials of the intervention and the overall program objective of successful RTW for people with depression. An empirical study of the efficacy of CWH is currently underway which should provide added insight and understanding into this intervention.

Conclusions: The application of IM to CWH illustrates the theoretical underpinnings of the treatment intervention and assists with better understanding the linkage between intervention elements and intervention objective. Applying IM to deconstruct an existing program (rather than create a program) presents an alternate application of the IM tool which can have implications for other programs in terms of enhancing understanding, grounding in theoretical foundations, communicating program design, and establishing a basis for program evaluation and improvement.

Keywords: Intervention mapping, Cognitive work hardening, Return-to-work, Depression, Program planning

\section{Background}

Cognitive work hardening $(\mathrm{CWH})$ is a treatment intervention for preparing people off work due to depression to return to work following a disability leave $[1,2]$. It is based on the same principles as classical work hardening (discussed in the following section on Principles of work hardening) but applies the concepts to the mental health domain [1]. CWH fills a gap in the health care system where there has been targeted intervention to prepare for

\footnotetext{
* Correspondence: adeena.wisenthal@queensu.ca

Queen s University, School of Rehabilitation Therapy, Kingston, ON, Canada
}

return to work (RTW) following an injury (e.g., physical work hardening) but there has been no comparable intervention in the mental health domain.

The need for a specific intervention to address the RTW needs of people with depression is supported by evidence related to the prevalence of mental illness, and depression in particular, and its impact on work productivity. In Canada, mental health disorders account for $25 \%$ of all diseases with $13 \%$ attributable to depression alone [3]. The World Health Organization predicts that by 2020 , depression will be the leading cause of disability 
worldwide, second only to heart disease [4]. Lost productivity per year due to mental health problems in Canada has risen from \$14 billion (1999) to \$33 billion (2004) with mental illness related disability claims accounting for one third of workplace claims approximately $70 \%$ of workplace costs [3-6]. Dewa et al. [3] studied the rising costs associated with poor mental health among workers internationally. They found similar trends in costs due to lost productivity and absenteeism resulting from mental health problems among many countries such as Sweden (more than $2 / 3$ of costs), The Netherlands ( 1.44 billion annually), England (30\% of absences due to stress), and the United States (average depression-related absenteeism productivity loss is equivalent to $\$ 8.3$ billion).

Depression is one of the most common mental disorders in the workforce $[7,8]$. It impacts an employees health, functioning, life satisfaction, and overall selfesteem. It typically results in decreased energy, fatigue, poor sleep, diminished/loss of appetite, feelings of worthlessness, hopelessness, and apathy $[9,10]$. Many cognitive deficits are associated with depression including impairments in concentration, memory, attention, and decision making. These problems can interfere with the ability to meet the cognitive, emotional and behavioural demands of a job [11-13]. In addition, these forms of work disability can contribute to the stigma of mental illness that is prevalent in workplaces, fuelling the assumption that competence to work is compromised $[14,15]$.

A person no longer able to work due to depression may go on a medical disability leave. During this time, treatment may be available in the form of psychotropic medications, psychotherapy, and psychological support. These treatments can be effective in helping to alleviate depression and its functional impacts. They are not, however, specifically aimed at preparing the person to return to work.

$\mathrm{CWH}$ addresses this intervention gap by targeting a broad range of functional issues that people with depression face in their workplaces which are critical for resuming job duties and achieving RTW success. These include the cognitive skills required to assume job duties and meet work demands, the coping skills required to manage work-related stress and deal with interpersonal issues, and the overall stamina and functional ability to adopt a work routine and adhere to a work schedule [1,2].

The purpose of this paper is to formalize a structured framework for CWH by integrating theory and practice using the structured process of Intervention Mapping (IM). The IM process provides a systematic framework for planning, designing, and implementing health promotion programs $[16,17]$. This paper shows how IM can also be used to deconstruct an existing intervention for the purpose of analysis, communication, and improvement. The analysis in this paper has resulted in a structured and detailed program theory for the CWH intervention consistent with the goals of program theory evaluation [18].

There are several approaches for program evaluation [18-20]. IM was chosen for the current program analysis because its inherent structured step-wise approach is ideal for making linkages between program elements and expected program outcomes. Furthermore, IM has been used by other researchers to tailor programs for targeted groups (e.g., mental disorders) as well as targeted domains (e.g., occupational health) $[21,22]$ both directly relating to the target population served by the $\mathrm{CWH}$ intervention. Empirical research is currently being conducted to study the efficacy of CWH which should complement the current analysis.

\section{Principles of work hardening}

$\mathrm{CWH}$ is grounded in the principles of classical work hardening which was developed in the 1970 s to address the needs of injured workers [23-27]. While classical work hardening is applicable to a wide range of disabilities, in practice it has almost exclusively been applied to people with physical injuries. For the purpose of this paper, the term physical work hardening $(\mathrm{PWH})$ refers to the application of work hardening to this population.

Both physical and cognitive forms of work hardening are rooted in common underlying principles while the differences are based on the functional and work-related needs of the population they specifically address. Both forms of work hardening use graded work activities to simulate a person s actual work tasks and demands. They both aim to improve a clients work performance skills to enable the safe and productive return to the workforce [1,2,23-27].

The goals of graded work activities in PWH encompass the neuromuscular aspects of an injury; in $\mathrm{CWH}$, graded work activities focus on the cognitive aspects of the clients condition. RTW outcomes are enhanced in PWH by increasing physical endurance, pain management, injury prevention, pacing and application of ergonomic principles [26-28] while they are enhanced in CWH by increasing mental stamina, mental fatigue management, coping skills, as well as pacing, and application of ergonomic principles [1,2].

Table 1 illustrates how the elements of both forms of work hardening compare in terms of physical versus cognitive components. For example, managing one s pain is often a critical RTW success factor for people with musculoskeletal problems [28] whereas (mental) fatigue management is critical among people returning to work following depression $[29,30]$. Both affect one s ability to increase work tolerance and therefore RTW readiness. In addition, an education component is common for both these work hardening populations. PWH clients learn about injury prevention techniques and $\mathrm{CWH}$ clients 
Table 1 Overall comparison of physical work hardening and cognitive work hardening

\begin{tabular}{lll}
\hline & Physical work hardening & Cognitive work hardening \\
\hline Identified needs & Prepare injured workers to RTW & Prepare employees with depression to RTW \\
\hline Program outcome & Facilitate a safe (and preferably early) RTW & Facilitate a safe (and preferably early) RTW \\
\hline Main elements & Individualized & Individualized \\
& Physical conditioning & Cognitive skills conditioning \\
& Pain management & Fatigue management \\
& Job specific work simulations & Job specific work simulations \\
& Education injury prevention, pacing, ergonomics & Education coping skills/strategies, pacing, ergonomics \\
\hline
\end{tabular}

benefit from coping skills training. Both groups benefit from education on pacing and ergonomic principles as these have been found to impact employee functioning, productivity, and mental health [31-33].

\section{Cognitive work hardening}

CWH is a multi-element intervention, typically offered by an occupational therapist (OT) in a simulated work setting preferably in the community away from a clinic environment $[1,2]$. Consistent with principles of occupational therapy practice, the intervention is grounded in the analysis of the clients job and the work environment in which the client works. Key occupational performance issues are identified by the client in an intake interview (and supported by medical documentation and other file data) and typically include fatigue, cognitive impairments (e.g., poor concentration, reduced memory, difficulty multitasking), interpersonal issues (e.g., effective communication, conflict management), and reduced coping skills (e.g., time management, organizational skills, goal setting). These performance issues are matched to work demands obtained from a job description and form the basis of the $\mathrm{CWH}$ intervention rendering the strategies selected individualized, highly relevant and enabling of a collaborative relationship with the client served.

In addition to the building of key cognitive and coping skills, interpersonal and organizational competencies to deal with work-related situations are typically addressed. Educational components support the development of effective coping skills, communications strategies, and approaches to facilitate the handling of workplace issues. Interventions that have an educational component contribute to ones sense of well-being, sense of control and empowerment which can contribute to success at work $[34,35]$.

A structured work schedule is a critical component of CWH. It provides the client a routine of meaningful and work-related activities which is typically lacking when off work on disability. Structure to the day can assist with improving feelings of self-esteem, enhancing motivation and offsetting general feelings of hopelessness that are often reported by people who experience mental illness [36]. The progressive work schedule that is inherent in $\mathrm{CWH}$, together with the gradual increase in cognitive skill development, enables the client to build stamina and the levels of energy required to match work demands. Since fatigue and reduced energy are commonly associated with depression and have been found to have a negative effect on work performance [29,37], stamina and energy are addressed in $\mathrm{CWH}$ with close attention to the balance of work-life demands and the importance of maintaining meaningful activity participation outside of the realm of the workplace.

Through the CWH process clients become aware of their functioning and gain insight into their strengths and limitations, which can have implications for RTW. More specifically, coping skills are developed, stamina is enhanced, a routine is established, and other work-related skills are gained thereby preparing the client to meet work demands while experiencing success within the $\mathrm{CWH}$ simulated work environment. These gains provide the client with self-confidence to return to work. Feeling that one has the competence and ability to perform ones job can contribute to self-efficacy, which has been found to be an essential factor in the work rehabilitation process impacting RTW outcomes [38,39]. Indeed, acquiring self-efficacy can improve self-esteem and reduce selfstigma which is often a barrier to social activity and employability [40].

\section{Methods}

IM has been used to create new programs to address problems in health care either through original design [21,41-43] or by adapting an existing intervention to meet the needs of a different population $[22,44,45]$. In particular, some researchers have used the IM approach to develop workplace interventions for employees on leave due to mental disorders based on existing programs for workers with musculoskeletal conditions [22,45]. Given that CWH emerged from the more established PWH, IM is used in this paper to examine overall program and performance objectives for both forms of work hardening. The IM protocol is then used to deconstruct the $\mathrm{CWH}$ intervention for a more detailed analysis of its objectives, 
tools and materials, and linkages to the underlying theories and models providing increased insight into the application of work hardening to the mental health population.

IM is considered a six step process with each step consisting of several tasks which, once completed, set the stage for the next step (Figure 1). The process is an iterative one, moving back and forth between tasks and steps as information and perspectives emerge from various activities. The process is cumulative with each step being based on the previous step in an effort to be comprehensive in the planning and maximize the potential effectiveness of the intervention/program $[17,46]$.

IM Step 1 is implicit in this analysis and yields the overall program objective of successful return-to-work for both $\mathrm{PWH}$ and CWH applied to their respective populations.
Step 2, Tasks 1 and 2 are used to examine the similarities and differences of these two interventions through variations in each of their overall program objectives, behavioural and environmental outcomes, and performance objectives. Step 2, Tasks 3 and 4 focus on CWH and are used to select changeable behaviour determinants of performance objectives for the behavioural and environmental outcomes with a matrix of change objectives being created that links the determinants to performance objectives. Step 3 is then used to select theoretical methods that match to the behaviour determinants and are then linked to practical strategies largely drawn from direct experience with the CWH intervention. Step 4 and Step 5 are not applicable in the current analysis because they relate to program creation and implementation whereas $\mathrm{CWH}$ is an

\begin{tabular}{|c|c|c|}
\hline \multirow[b]{3}{*}{1} & $\begin{array}{l}\text { Step } 1 \\
\text { Needs Assessment }\end{array}$ & $\begin{array}{l}\text { - Establish a participatory planning group } \\
\text { - Conduct the needs assessment } \\
\text { - Assess community capacity } \\
\text { - Specify program goals for health and quality } \\
\text { of life }\end{array}$ \\
\hline & $\begin{array}{l}\text { Step } 2 \\
\text { Matrices }\end{array}$ & $\begin{array}{l}\text { - State outcomes for behavior and } \\
\text { environmental change } \\
\text { - State performance objectives } \\
\text { - Select important and changeable } \\
\text { determinants } \\
\text { - Create a matrix of change objectives }\end{array}$ \\
\hline & $\begin{array}{l}\text { Step } 3 \\
\text { Theory-based intervention } \\
\text { methods and practical } \\
\text { applications }\end{array}$ & $\begin{array}{l}\text { - Generate program ideas with the planning } \\
\text { group } \\
\text { - Identify theoretical methods } \\
\text { - Choose program methods } \\
\text { - Select or design practical applications } \\
\text { - Ensure that applications address change } \\
\text { objectives }\end{array}$ \\
\hline \multirow{3}{*}{ Evaluation } & $\begin{array}{l}\text { Step } 4 \\
\text { Intervention Program }\end{array}$ & $\begin{array}{l}\text { - Consult intended participants and } \\
\text { implementers } \\
\text { - Create program themes, scope, sequence, } \\
\text { and materials list } \\
\text { - Prepare design documents } \\
\text { - Review available program materials } \\
\text { - Draft program materials and protocols } \\
\text { - Pretest program materials and protocols } \\
\text { - Produce materials and protocols }\end{array}$ \\
\hline & $\begin{array}{l}\text { Step } 5 \\
\text { Adoption and Implementation }\end{array}$ & $\begin{array}{l}\text { - Identify potential adopters and implementers } \\
\text { - Reevaluate the planning group } \\
\text { - State program use outcomes and } \\
\text { performance objectives } \\
\text { - Specify determinants for adoption and } \\
\text { implementation } \\
\text { - Create a matrix of change objectives } \\
\text { - Select methods and practical applications } \\
\text { - Design interventions for adoption and } \\
\text { implementation }\end{array}$ \\
\hline & $\begin{array}{l}\text { Step } 6 \\
\text { Evaluation Plan }\end{array}$ & $\begin{array}{l}\text { - Review the program logic model } \\
\text { - Write effect evaluation questions } \\
\text { the determinants } \\
\text { - Write process evaluation questions } \\
\text { - Develop indicators and measures } \\
\text { - Specify evaluation design }\end{array}$ \\
\hline
\end{tabular}

Figure 1 Intervention mapping process [17]. 
existing treatment intervention. Step 6 is discussed in terms of its value in monitoring the $\mathrm{CWH}$ intervention under discussion, fine tuning details to enhance outcome, and contributing to research and clinical knowledge to advance health outcomes.

An ethics statement is not included in this paper as there was no study conducted and there was no research conducted on human subjects.

\section{Results}

\section{IM Step 1: Needs assessment}

A Needs Assessment review is not within the scope of this analysis because CWH is an existing program and its creation is not being addressed in this paper. Nevertheless, many of the elements comprising this step (e.g., discussion with stakeholders, examination of client needs) were initially used to adapt PWH to the client population served by CWH [1].

The output of this step is the overall program objective which is then used to drive the remaining IM steps. In $\mathrm{PWH}$, the overall program objective is successful $R T W$ for people with a physical injury. In CWH, the program objective is successful RTW for people with depression.

\section{IM Step 2: Matrices of change objectives}

Tasks 1 and 2: Behavioural/environmental outcomes and Performance objectives

The first task in IM Step 2 is to state the behavioural and environmental outcomes that need to be achieved in order to reach the overall program objective. The next task is to specify what change is necessary in the behavioural and environmental outcomes by stating performance objectives. Performance objectives refer to the effects of the intervention in terms of behaviour that should be learned or changed (behavioural outcome) or aspects of the environment that need to be changed (environmental outcome) $[17,47]$. In both forms of work hardening, the behavioural outcome is Client is ready to $R T W$ while the environmental outcome is RTW plan is in place. Tables 2 and 3 present the performance objectives for $\mathrm{PWH}$ and $\mathrm{CWH}$, respectively.

Tolerance to work hours (performance objective 2) is a common objective to both forms of work hardening but is achieved in different ways through related performance objectives 3 and 4 . For example, pain is often a limiting factor for an injured workers work tolerance whereas (mental) fatigue often limits work tolerance for persons with depression.

Attention now shifts to focus solely on the CWH intervention under study. The IM structure is used to further deconstruct $\mathrm{CWH}$ in order to enhance the understanding of the intervention and to provide a systematic way of describing the intervention and the underlying theory.
Table 2 Performance objectives for behavioural and environmental outcomes: PWH

Program objective: Successful return-to-work for people with physical injury

\begin{tabular}{|c|c|}
\hline $\begin{array}{l}\text { Behavioural } \\
\text { outcome }\end{array}$ & Performance objectives \\
\hline \multirow[t]{6}{*}{$\begin{array}{l}\text { Client is ready } \\
\text { to RTW }\end{array}$} & $\begin{array}{l}\text { 1. Client identifies RTW barriers and accepts } \\
\text { proposed treatment plan }\end{array}$ \\
\hline & $\begin{array}{l}\text { 2. Client has the work tolerance to meet minimally } \\
\text { required work hours }\end{array}$ \\
\hline & 3. Client has physical tolerance to meet job demands \\
\hline & 4. Client has pain management strategies \\
\hline & 5. Client is aware of injury prevention strategies \\
\hline & 6. Client has confidence in ability to return to work \\
\hline $\begin{array}{l}\text { Environmental } \\
\text { outcome }\end{array}$ & Performance objectives \\
\hline \multirow[t]{3}{*}{$\begin{array}{l}\text { RTW plan is } \\
\text { in place }\end{array}$} & $\begin{array}{l}\text { 1. GRTW schedule is designed and agreed upon by } \\
\text { stakeholders }\end{array}$ \\
\hline & 2. Workplace accommodations are provided \\
\hline & $\begin{array}{l}\text { 3. Clients strengths and limitations are assessed for } \\
\text { job match }\end{array}$ \\
\hline
\end{tabular}

GRTW = gradual return-to-work.

Tasks 3 and 4: Select determinants and Create matrices of change objectives

By breaking down each performance objective into its learning objectives (for the behavioural outcome) and change objectives (for the environmental outcome) important and changeable behaviour determinants are selected. This results in matrices of change objectives that are

Table 3 Performance objectives for behavioural and environmental outcomes: CWH

\begin{tabular}{|c|c|}
\hline \multicolumn{2}{|c|}{$\begin{array}{l}\text { Program objective: Successful return-to-work for people with } \\
\text { depression }\end{array}$} \\
\hline $\begin{array}{l}\text { Behavioural } \\
\text { outcome }\end{array}$ & Performance objectives \\
\hline \multirow[t]{6}{*}{$\begin{array}{l}\text { Client is ready } \\
\text { to RTW }\end{array}$} & $\begin{array}{l}\text { 1. Client identifies RTW barriers, concurs with and } \\
\text { commits to treatment plan }\end{array}$ \\
\hline & $\begin{array}{l}\text { 2. Client has the work tolerance to meet minimally } \\
\text { required work hours }\end{array}$ \\
\hline & 3. Client has cognitive skills to meet job demands \\
\hline & 4. Client has fatigue management strategies \\
\hline & $\begin{array}{l}\text { 5. Client has coping skills/strategies to deal with workplace } \\
\text { interpersonal, organizational and task demands }\end{array}$ \\
\hline & 6. Client has confidence in ability to return to work \\
\hline $\begin{array}{l}\text { Environmental } \\
\text { outcome }\end{array}$ & Performance objectives \\
\hline \multirow[t]{3}{*}{$\begin{array}{l}\text { RTW plan is } \\
\text { in place }\end{array}$} & $\begin{array}{l}\text { 1. GRTW schedule is designed and agreed upon by } \\
\text { stakeholders }\end{array}$ \\
\hline & 2. Workplace accommodations are provided \\
\hline & $\begin{array}{l}\text { 3. Client s strengths and limitations are assessed for } \\
\text { job match }\end{array}$ \\
\hline
\end{tabular}

GRTW = gradual return-to-work. 
specific to each performance objective. Determinants selected in this current analysis are based on those set out by Bartholomew et al. [16] as well as those used by other researchers [17,22,41,46-48].

The determinants of attitude, norms, and self-efficacy can be traced to the de Vries ASE model of behaviour intention [49]. This model suggests that a persons intention to perform a certain behaviour is determined by personal conceptions regarding the behaviour (attitude), the social pressures by others regarding the behaviour (norms), and personal belief in ones ability to engage in the behaviour (self-efficacy). The realization of the behaviour is dependent on a positive intention but also requires the person having the skills/abilities to carry out the behaviour. This model is based on the Fishbein and Ajzen model for change behaviour [50] and Banduras Social Learning Model [51]. These three determinants, in addition to risk perception and knowledge, have been successfully utilized by other researchers applying IM to RTW interventions [22,41]. The determinant outcome expectations has been studied by Bartholomew et al. [16,17] and is also included in the current analysis. Skills is also used as a determinant based on de Vries [49] contention that this is a related factor to behaviour change and the assertion by Kok et al. [46] that having the necessary skills to perform the behaviour is among the necessary and sufficient determinants for behaviour change.

The environmental determinants were selected based on evidence from the literature related to determinants already used in the development of RTW interventions for employees with musculoskeletal conditions as well as for employees with mental health problems [22,41] in addition to other related literature [17]. These include norms, support, resources, organizational climate, and safety and equality. In this paper, the concept norms is used to refer to the norms in the clients workplace; most notably, related to the job tasks. Safety and equality refers to feeling secure in ones workplace. It includes an environment which is psychologically safe from provoking relapse where everyone is treated fairly and given what they need to succeed at their work (e.g., accommodations, if required) and an equal environment is one where ones human rights are considered. The accommodation process addresses both these aspects and is therefore an inherent part of this external determinant.

Table 4 presents an example of learning objectives that are associated with the performance objective: Client identifies $R T W$ barriers, concurs with and commits to treatment plan . This performance objective is one among the six already presented that are associated with the behavioural outcome: Client is ready to $R T W$. Determinants of behaviour change are presented across the top of the matrix and include risk perception and knowledge, attitude, skills, self-efficacy, and outcome expectations. For each determinant, a change objective is created that links that determinant to the performance objective. The same process is applied with each of the other performance objectives resulting in a matrix being created by linking each determinant with each performance objective.

Table 5 presents an example of change objectives which are associated with the performance objective: GRTW is designed and agreed upon by stakeholders . This performance objective is one among the three already presented that are associated with the environmental outcome: $R T W$ plan is in place. Determinants of behaviour change are presented across the top of the matrix and include norms, support, resources, organizational climate, and safety $\mathcal{E}$ equality. For each determinant, a change objective is again created linking that determinant to the performance objective. The same process is applied with each of the other performance objectives resulting in a matrix being created by linking each determinant with each performance objective.

\section{Step 3: Theory-based intervention methods and practical applications}

Step 3 of the IM process involves choosing methods and practice strategies that are theoretically grounded and clarifying the underlying mechanisms that contribute to change objectives and ultimately program objectives [17]. This aligns with what Bartholomew et al. [17] describe as the causal chain from determinants to objectives to methods to applications (p. 313) which they note is often not reported in program descriptions; hence, it is difficult to judge the theory and evidence base behind what planners have chosen to include in

Table 4 Example of learning objectives based on combination of performance objective and determinants

\begin{tabular}{|c|c|c|c|c|c|}
\hline \multirow{2}{*}{$\begin{array}{l}\text { Performance } \\
\text { objectives for client }\end{array}$} & \multicolumn{5}{|l|}{ Learning objectives } \\
\hline & $\begin{array}{l}\text { Risk perception and } \\
\text { knowledge }\end{array}$ & Attitude & Skills & Self-efficacy & $\begin{array}{l}\text { Outcome } \\
\text { expectations }\end{array}$ \\
\hline $\begin{array}{l}\text { Client identifies RTW } \\
\text { barriers, concurs with } \\
\text { and commits to } \\
\text { treatment plan. }\end{array}$ & $\begin{array}{l}\text { Client identifies occupational } \\
\text { performance issues and how } \\
\text { they impact RTW readiness. }\end{array}$ & $\begin{array}{l}\text { Client understands nature } \\
\text { of intervention and has a } \\
\text { positive attitude towards it. }\end{array}$ & $\begin{array}{l}\text { Client recognizes } \\
\text { occupational } \\
\text { performance issues. }\end{array}$ & $\begin{array}{l}\text { Client believes } \\
\text { occupational performance } \\
\text { issues can be overcome. }\end{array}$ & $\begin{array}{l}\text { RTW barriers are } \\
\text { addressed. }\end{array}$ \\
\hline
\end{tabular}


Table 5 Example of change objectives based on combination of performance objective and determinants

\begin{tabular}{llllll}
\hline $\begin{array}{l}\text { Performance } \\
\text { objectives for } \\
\text { environment }\end{array}$ & \multicolumn{2}{l}{ Change objectives } & & & \\
\cline { 2 - 6 } & Norms & Support & Resources & $\begin{array}{l}\text { Organizational } \\
\text { climate }\end{array}$ & Safety \& Equality \\
\hline $\begin{array}{lllll}\text { GRTW is designed } \\
\text { and agreed upon } \\
\text { by stakeholders. }\end{array}$ & $\begin{array}{l}\text { GRTW schedule } \\
\text { (e.g., } 68 \text { weeks). }\end{array}$ & $\begin{array}{l}\text { OT reviews GRTW with } \\
\text { client and addresses } \\
\text { questions/concerns. }\end{array}$ & $\begin{array}{l}\text { Roles of OT, insurer, and } \\
\text { employer in GRTW process } \\
\text { are clearly delineated. }\end{array}$ & $\begin{array}{l}\text { Insurer reviews GRTW } \\
\text { with employer for } \\
\text { clarity and buy-in. }\end{array}$ & $\begin{array}{l}\text { RTW concerns are addressed; } \\
\text { questions answered. } \\
\text { GRTW plan is accepted by } \\
\text { client and all stakeholders. }\end{array}$ \\
\hline
\end{tabular}

their intervention. This step involves studying each determinant and the methods of behaviour change related to each determinant both at the individual and the environment level. It is precisely this step, discussed below, that explores methods and theories and links them to the tools/materials used in the CWH intervention. In so doing, a better understanding of the theoretical underpinnings of the CWH process that can explain the intervention outcome $R T W$ preparation for people with depression is achieved. This is consistent with the goals of process evaluation which espouses to study program implementation in order to understand the relationship between program elements and program outcome(s) [19].

The detailed analysis of IM Step 3 provides insight into how each determinant relates to a theoretical method, a strategy, and ultimately to CWH tools. Matching practical applications to theory has affirmed strategies such as collaboration, targeted questioning, engagement in meaningful activity, empowerment, and education. Tools and materials are understood as having been selected as concrete and tangible ways of implementing a particular strategy. These items ultimately comprise the elements of the CWH intervention (Table 6).

The detailed work of IM Step 3 establishes the relationship among program tools/materials, determinants, and performance objectives. Table 7 illustrates how select $\mathrm{CWH}$ tools/materials are linked to and shown to support a determinant and, in turn, how the determinant is linked to and is shown to support a performance objective. This draws a much clearer association between performance objectives and the program elements (i.e. tools/materials) which together contribute to the overall CWH program objective of RTW.

Special attention is drawn in this analysis to self-efficacy as a determinant of behaviour change because it is linked to the tool work simulations which are a fundamental element of CWH. Work simulations are used to simulate a clients pre-disability task demands in order to facilitate cognitive skill development. They are developed by the OT, with input from the client, through a task analysis of the clients work duties and are graded in complexity as the client progresses in the CWH process.
Engagement in meaningful occupation is the central process of change in $\mathrm{CWH}$ and guides the occupational therapy process $[1,2]$. Indeed engagement is a hallmark of the occupational therapy profession and a key concept of the Canadian Model of Occupational Performance and Engagement (CMOP-E) which presents an occupational perspective that includes and extends beyond occupational performance to include engagement [52]. In this way, the link is made between intervention tools and determinants through underlying occupational therapy theory which guides practice through methods and strategies.

The determinant self-efficacy is also informed by Banduras Social Learning Theory [51] which indicates the importance of a persons personal mastery expectations regarding a desired behaviour. Self-efficacy refers to ones beliefs about ones ability to perform a specific behaviour. Individuals with low self-efficacy will likely avoid situations and/or not engage in behaviours that they feel unable to cope with or perform. Individuals with high levels of self-efficacy will be more likely to engage in behaviour in which they feel more confident to perform and will likely persist with behaviours that may become difficult which in turn increases their self-efficacy expectations further. Through engaging in meaningful work simulations in $\mathrm{CWH}$, an individual gains mastery through personal performance accomplishments which instills confidence and reinforces ones sense of self-efficacy. Learning through experience is one of four main sources of self-efficacy that Bandura highlighted in his theory and has been noted to be the most effective $[51,63]$.

Drawing from the work of van Oostrom et al. [22] and Vermeulen et al. [41], the RTW process requires not only ones attitude, social influence, and selfefficacy to drive ones intention for behaviour change but must also consider the influence of barriers and facilitators together with knowledge and skills to achieve RTW. With this in mind, focus on occupational performance issues through targeted questioning and discussions contribute to the role that 
Table 6 Example of determinants linked to theories and practical strategies

\begin{tabular}{|c|c|c|c|c|}
\hline $\begin{array}{l}\text { Determinant } \\
(\mathrm{L})=\text { Learning } \\
(\mathrm{C})=\text { Change }\end{array}$ & $\begin{array}{l}\text { Methods } \\
\text { (from theory) }\end{array}$ & Theory & Strategy & Tools/Materials \\
\hline \multirow{8}{*}{$\begin{array}{l}\text { Risk perception } \\
\text { \& knowledge (L) }\end{array}$} & \multirow{6}{*}{ Personalize risk } & CMOP-E [52] & Client-centred & Guided questions \\
\hline & & \multirow[t]{5}{*}{ PEO [53] } & Collaboration & Brochures, handouts \\
\hline & & & Targeted questioning & \multirow{4}{*}{$\begin{array}{l}\text { Discussion of occupational } \\
\text { performance issues/barriers to RTW }\end{array}$} \\
\hline & & & $\begin{array}{l}\text { Occupational performance } \\
\text { issues }\end{array}$ & \\
\hline & & & Meaningful occupation/activity & \\
\hline & & & Written \& verbal information & \\
\hline & Discussion & \multirow[t]{2}{*}{ ELM $[54,55]$} & Discussion & \multirow[t]{2}{*}{ Personalized discussions } \\
\hline & Elaboration & & Self-reflection & \\
\hline \multirow[t]{7}{*}{ Self-efficacy (L) } & \multirow{2}{*}{$\begin{array}{l}\text { Enactive mastery } \\
\text { experiences }\end{array}$} & \multirow{2}{*}{$\begin{array}{l}\text { Bandura s Social Learning } \\
\text { Theory [51] }\end{array}$} & \multirow{2}{*}{$\begin{array}{l}\text { Personal performance } \\
\text { accomplishments of tasks }\end{array}$} & Work simulations/activity selection \\
\hline & & & & Task analysis \\
\hline & Verbal persuasion & Rotter s Locus of Control [56] & $\begin{array}{l}\text { Reinforcing messages } \\
\text { regarding capabilities }\end{array}$ & Graded activity \\
\hline & \multirow{3}{*}{$\begin{array}{l}\text { Engagement in } \\
\text { meaningful activity }\end{array}$} & Recovery Model $[57,58]$ & \multirow[t]{3}{*}{ Empowerment } & \multirow{2}{*}{$\begin{array}{l}\text { Exploration of linkages between performance, } \\
\text { self-efficacy, occupational performance }\end{array}$} \\
\hline & & CMOP-E & & \\
\hline & & PEO & & Discussions strengths, work ability \\
\hline & $\begin{array}{l}\text { Self-monitoring of } \\
\text { behavior }\end{array}$ & Theory of Self-Regulation [59] & $\begin{array}{l}\text { Monitoring of newly acquired } \\
\text { skills (e.g., assertiveness) }\end{array}$ & $\begin{array}{l}\text { Client keeps a record of situations in which } \\
\text { they practiced assertiveness to review with OT }\end{array}$ \\
\hline \multirow[t]{13}{*}{ Norms (C) } & \multirow{5}{*}{$\begin{array}{l}\text { Cognitive skill } \\
\text { development }\end{array}$} & \multirow{5}{*}{$\begin{array}{l}\text { The Dynamic Interactional } \\
\text { Model of Cognition }[60,61]\end{array}$} & Approach to task & Job description \\
\hline & & & \multirow{4}{*}{$\begin{array}{l}\text { Development of task skill } \\
\text { to match task demands }\end{array}$} & Functional assessments \\
\hline & & & & Task analysis \\
\hline & & & & Work simulations \\
\hline & & & & Graded activity \\
\hline & \multirow{2}{*}{$\begin{array}{l}\text { Participation in } \\
\text { meaningful activity }\end{array}$} & CMOP-E & \multirow[t]{2}{*}{ Adoption of work routine } & \multirow[t]{2}{*}{ GRTW schedule } \\
\hline & & PEO & & \\
\hline & \multirow{6}{*}{$\begin{array}{l}\text { Intrapersonal skill } \\
\text { development }\end{array}$} & \multirow[t]{2}{*}{ Appraisal Model of Coping [62] } & Assertiveness training & Role plays \\
\hline & & & Stress management & Vignettes \\
\hline & & \multirow{2}{*}{$\begin{array}{l}\text { Bandura s Social Learning } \\
\text { Theory }\end{array}$} & Education & \multirow[t]{4}{*}{ Audiovisual resources } \\
\hline & & & Repetition & \\
\hline & & Rotter s Locus of Control & Practice & \\
\hline & & & Problem-solving & \\
\hline \multirow{4}{*}{$\begin{array}{l}\text { Safety \& } \\
\text { equality (C) }\end{array}$} & \multirow{4}{*}{$\begin{array}{l}\text { Duty to accommodate } \\
\text { process }\end{array}$} & CMOP-E & Task analysis & Job descriptions \\
\hline & & CMCE & Functional analysis & Work simulations \\
\hline & & \multirow[t]{2}{*}{ CPPF } & \multirow[t]{2}{*}{ Job demands analysis } & Accommodation process \\
\hline & & & & $\begin{array}{l}\text { Discussions with client, insurer, } \\
\text { employer }\end{array}$ \\
\hline
\end{tabular}

knowledge plays as a determinant of RTW in the CWH process. Clients are engaged in RTW preparation by examining their occupational performance issues as they relate to their cognitive functioning and skills, their environment (home/work), and the actual job demands at the workplace. This is consistent with client-centred models which stress that occupational performance and engagement result from the dynamic relationship between people, their occupations, and the environments in which they live, work, and play $[52,53]$.

\section{Step 4: Intervention program and Step 5: Adoption and implementation}

IM Step 4 and Step 5 involve program creation and implementation and are not applicable in this analysis 
Table 7 Example of CWH tools mapped to performance objectives

\begin{tabular}{llll}
\hline Tool & Determinant & Learning objective & Performance objective(PO) \\
\hline Work simulations & Self-efficacy & $\begin{array}{l}\text { Client experiences markers of improved work performance } \\
\text { contributing to the belief that s/he is ready to RTW }\end{array}$ & $\begin{array}{l}\text { Client has the confidence in } \\
\text { his/her ability to RTW } \\
\text { (PO \#6) }\end{array}$ \\
$\begin{array}{llll}\text { Videos, role } \\
\text { plays, coaching }\end{array}$ & Skills & $\begin{array}{l}\text { Client has the ability to apply assertiveness skills to } \\
\text { personal \& work situations }\end{array}$ & $\begin{array}{l}\text { Client has the coping skills to deal } \\
\text { with workplace stress (PO \#5) }\end{array}$ \\
\hline $\begin{array}{llll}\text { Education } & \text { Risk perception \& knowledge } & \text { Client learns the value of pacing } & \text { Client has fatigue management } \\
& & & \text { strategies } \\
& & \text { (PO \#4) }\end{array}$ \\
\hline
\end{tabular}

where IM is being used to deconstruct an existing intervention.

\section{Step 6: Evaluation}

IM Step 6 can be applied as it would be in the usual IM process for a newly designed program for the purpose of program monitoring and evaluation. This is indeed an important step that guides and enriches health education research through potential program enhancement $[16,17]$.

Using IM to deconstruct CWH provides increased insight into the interventions underlying models and theory of change which, according to Bartholomew et al. [17], drives the evaluation process. In addition, the current analysis highlights the relationship between intervention change/learning objectives, behaviour change techniques, and intervention tools/materials within the over arching theoretical base of the intervention. This allows for evaluation of process and effect of the intervention to determine if any changes are needed for program improvement [43,64].

Through this analysis, self-efficacy (and its impact on one s belief in ones work ability) as well as fatigue emerged as critical RTW success factors; however, it became apparent that no standardized measurement tools were implemented to measure either of these constructs. The inclusion of such measurement tools emerged as an intervention improvement to gage work ability and fatigue status from intake (baseline) to discharge (program completion). Scores on standardized measures and difference scores may indeed have implications for RTW success. This is being studied in the first author s current research study.

Although a focused process evaluation is not within the scope of this analysis, a few aspects of the process evaluation approach are worth noting. Implementation fidelity refers to the fidelity with which a program is implemented and has been discussed as an important factor mediating between interventions and their outcomes $[19,20]$. This may indeed influence the success of the $\mathrm{CWH}$ intervention and would need to be addressed in knowledge transfer activities related to the $\mathrm{CWH}$ intervention (e.g., workshops, training manuals). Contextual issues [19] include resource considerations such as adequately trained therapists to implement the $\mathrm{CWH}$ intervention, stakeholders that would be willing to support $\mathrm{CWH}$ for their clients/employees, and the physical environment consistent with the ideals of $\mathrm{CWH}$ (e.g., communitybased, non-clinical).

Deconstruction of an existing intervention contributes to the field of health research. Feedback from this analysis builds on the fundamental goal of evaluation program enhancement by adding a layer of insight into the interventions underlying theoretical models and strategies which can then strengthen the body of knowledge used to address other health issues. Indeed, learnings obtained regarding models and in vivo strategies have the potential to influence their usage and possible further evolvement.

\section{Discussion}

This paper provided a theoretical analysis of CWH by adapting the IM process to deconstruct the treatment intervention. $\mathrm{CWH}$ is a treatment intervention designed to prepare people to return to work following a depression and is based on established work hardening principles. Providing opportunity for mastery prior to returning to work helps to mitigate the prevalence of stigma against depression in todays workplaces [65].

As part of a strategy to familiarize the health care and vocational rehabilitation community with this tailored approach, communication, knowledge development, research and evaluation of the intervention is being undertaken and is enhanced by the systematic development of a formal program description. IM provided the framework with which to methodically analyze CWH to gain a better understanding and appreciation of its component parts and underlying theoretical foundation. At the same time, $\mathrm{CWH}$ served as an illustrative example of the adapted IM process which has been formulated and presented here.

The structured IM process provided a roadmap for the detailed intervention analysis of $\mathrm{CWH}$ that included establishing performance objectives and change objectives. Matrices were developed that linked determinants of behaviour change to performance objectives resulting in change objectives that were then mapped to $\mathrm{CWH}$ tools that are the basic elements of the intervention. 
Application of the IM protocol enabled the linking of strategies and tools to theories to analyze the intervention s underlying mechanisms that are believed to impact the desired intervention outcomes. Empirical study of the efficacy of the intervention and client feedback on useful intervention elements is currently underway, and findings should provide added insight and understanding into this intervention.

The current analysis contributes to the scientific literature and the clinical field by providing insight into $\mathrm{CWH}$ that is not only descriptive but is also theory-based thereby enhancing understanding of this treatment intervention. The sequential deconstruction of $\mathrm{CWH}$ has the potential to highlight gaps in the intervention which can then be addressed to improve the intervention and treatment outcome. This is consistent with the feedback loop that is inherent in the structured IM framework which consists of program evaluation for continued intervention improvement.

The IM structure provides a common language to share intervention content and rationale [64] and, indeed, using the IM tool to deconstruct an existing intervention contributes to the field of research through this shared language. In this way, the scientific knowledge base is enhanced through communication of an interventions underlying theoretical models, strategies, and program tools which can then be applied to other treatment interventions and health concerns thereby benefiting the broader research and clinical communities. In addition, intervention analysis encompasses in-depth study of intervention models and practical strategies that can lead to improvement and evolvement of these elements which can also enhance the body of scientific and clinical knowledge.

Although IM was originally designed as a program development tool, by embracing the application of its protocol as described in this paper, other existing interventions can be deconstructed to gain insight into their programs for the purpose of program description, evaluation and ultimately improved health outcomes. Adoption by more program designers and researchers results in a larger pool of interventions being systematically studied with findings informing the health research community and facilitating the exchange of best practices.

\section{Conclusions}

The use of IM to deconstruct an existing intervention proved to be a useful tool to systematically analyze and describe the interventions theoretical underpinnings which promotes knowledge sharing and lays the foundation for intervention evaluation and improvement. This approach has implications for other existing interventions where using a common systematic protocol provides a shared language enhancing knowledge exchange among practitioners and the research community.

\section{Abbreviations}

CWH: Cognitive work hardening; IM: Intervention mapping; RTW: Return to work; PWH: Physical work hardening; OT: Occupational therapist; GRTW: Gradual return-to-work; CMOP-E: Canadian Model of Occupational Performance and Engagement; PEO: Person Environment Occupation; ELM: Elaboration Likelihood Model; CMCE: Canadian Model of Client-Centred Enablement; CPPF: Canadian Practice Process Framework.

\section{Competing interests}

The authors declare that they have no competing interests.

\section{Authors contributions}

Both authors contributed to the concepts presented in this paper and both reviewed and approved the final manuscript. The detailed deconstruction specifically applied to CWH was carried out by AW as part of her doctoral research.

\section{Authors information}

AW, B.Sc. (OT), M.Ed., is a PhD Candidate in Rehabilitation Science at Queen s University in Kingston, Ontario. Her clinical practice spans over 20 years with a specialization in workplace mental health and return-to-work. TK, PhD, OT Reg (Ont), is a Professor in the School of Rehabilitation Therapy at Queen s University in Kingston, Ontario. Her research interests focus on the occupational lives of people with mental illness, with a special focus on productivity.

\section{Acknowledgements}

Other than the co-authors, there are no individuals or funding organizations who contributed directly or indirectly to this manuscript.

Received: 28 January 2014 Accepted: 14 October 2014

Published online: 12 December 2014

\section{References}

1. Wisenthal A: Occupational therapy provides the bridge back to work. Occup Ther Now 2004, 6:17 19.

2. Wisenthal A, Krupa T: Cognitive work hardening: a return-to-work intervention for people with depression. Work 2013, 45:423 430.

3. Dewa C, McDaid D, Ettner S: An international perspective on worker mental health problems: who bears the burden and how are costs addressed? Can J Psychiatr 2007, 52:346 356.

4. Murray C, Lopez A: The Global Burden of Disease: A Comprehensive Assessment of Mortality and Disability from Diseases, Injuries, and Risk Factors in 1990 and Projected to 2020. Geneva: World Health Organization; 1996.

5. Watson Wyatt Worldwide: Staying @ Work 2005: Making the connection to a healthy organization. Watson Wyatt Worldwide; 2005.

6. Wilson M, Joffe R, Wilkerson B: The unheralded business crisis in Canada: Depression at work. Toronto: GPC; 2000.

7. Myette T: Research on depression in the workplace: where do we go from here? J Occup Environ Med 2008, 50:492 500

8. Dewa C, Lesage A, Goering P, Caveen M: Nature and prevalence of mental illness in the workplace. Healthcare Papers 2004, 5:12 25.

9. Bruce ML: Depression and Disability. In Physical IIIness and Depression in Older Adults. Edited by Williamson GM, Shaffer DR, Parmelee PA. New York: Kluwer Academic/Plenum Publishers; 2000:11 29.

10. Kennedy S: Core symptoms of major depressive disorder: relevance to diagnosis and treatment. Dialogues Clin Neurosci 2008, 10:271 277.

11. Hammar A, Ardal G: Cognitive functioning in major depression - a summary. Front Hum Neurosci 2009, 3:1 7.

12. Gualtieri $C T$, Johnson $L G$, Benedict KB: Neurocognition in depression: patients on and off medication versus healthy comparison subjects. J Neuropsychiatry Clin Neurosci 2006, 18:217 225.

13. Miller D: Psychosocial issues and the return-to-work process. OT Pract Online, Am Occup Ther Assoc 2004, 9:16 20.

14. Krupa T, Kirsh B, Cockburn L, Gewurtz R: Understanding the stigma of mental illness in employment. Work 2009, 33:413 425.

15. Stuart H: Mental illness and employment discrimination. Curr Opin Psychiatry 2006, 19:522 526.

16. Bartholomew L, Parcel G, Kok G: Intervention mapping: a process for developing theory and evidence-based health education programs. Health Educ Behav 1998, 25:545 563. 
17. Bartholomew L, Parcel G, Kok G, Gottlieb N, Fernandez M: Planning Health Programs: an intervention mapping approach. 3rd edition. San Francisco: Jossey-Bass; 2011.

18. Rogers $P$, Petrosino A, Huebner T, Hacsi T: Program theory evaluation: practice, promise, and problems. N Dir Eval 2000, 87:5 13.

19. Saunders R, Evans M, Joshi P: Developing a process-evaluation plan for assessing health promotion program implementation: a how-to guide. Health Promot Pract 2005, 6:134 147

20. Carroll C, Patterson M, Wood S, Booth A, Rick J, Balain S: A conceptual framework for implementation fidelity. Implement Sci 2007, 2:1 9.

21. Koekkoek B, van Meijel B, Schene A, Hutschemaekers G: Development of an intervention program to increase effective behaviours by patients and clinicians in psychiatric services: intervention mapping study. BMC Health Serv Res 2010, 10:293.

22. van Oostrom S, Anema J, Terluin B, Venema A, de Vet $H$, van Mechelen W: Development of a workplace intervention for sick-listed employees with stress-related mental disorders: intervention mapping as a useful tool. BMC Health Serv Res 2007, 7:127.

23. Brewer C, Stroms B: The final phase of rehabilitation: work hardening. Orthop Nurs 1993, 12:9 15.

24. Demers L: Work Hardening: A Practical Guide. Stoneham, Massachusetts: Butterworth-Heinemann; 1992.

25. Ogden-Niemeyer L, Jacobs K: Work Hardening: State of the Art. N.J: Slack Incorporated; 1989.

26. Johnson L, Archer-Heese G, Caron-Powles D, Dowson T: Work hardening: outdated fad or effective intervention? Work 2001, 16:235 243.

27. Sang L, Eria L: Outcome evaluation of work hardening program for manual workers with work-related back injury. Work 2005, 25:297 305

28. Joy J, Lowy J, Mansoor J: Increased pain tolerance as an indicator of return to work in low-back injuries after work hardening. Am J Occup Ther 2001, 55:200 205.

29. Kessler R, White L, Birnbaum H, Qiu Y, Kidolezi Y, Mallett D, Swindle R: Comparative and interactive effects of depression relative to other health problems on work performance in the workforce of a large employer. JOEM 2008, 50:809 816.

30. Demyttenaere K, De Fruyt J, Stahl S: The many faces of fatigue in major depressive disorder. Int J Neuropsychopharmacol 2005, 8:93 105.

31. Dal Cason D: Ergonomic principles and tools for best interdisciplinary psycho-physical stress prevention. Work 2012, 41:3920 3922.

32. Rocha L, Debert-Ribeiro M: Working conditions, visual fatigue, and mental health among systems analysts in Sao Paulo, Brazil. Occup Environ Med 2004, 61:24 32 .

33. Wahlstrom J: Ergonomics, musculoskeletal disorders and computer work. Occup Med 2005, 55:168 176

34. Baynton M: Return to work: strategies for engaging the employee in the return-to-work process when mental health is a factor. OOHNA J 2010, 29:16 20.

35. Eklund $M$, Backstrom M: The role of perceived control for the perception of health by patients with persistent mental illness. Scand J Occup Ther 2006, 12:249 256 .

36. Mee J, Sumsion T: Mental health clients confirm the motivating power of occupation. Br J Occup Ther 2001, 64:121 128.

37. Johnson S: Depression and Fatigue. In Fatigue as a Window to the Brain. Edited by DeLuca J. Cambridge: Massachusetts Institute of Technology; 2007:157 172

38. Labriola M, Lund T, Christensen K, Albertson K, Bultmann U: Does self-efficacy predict return-to-work after sickness absence? A prospective study among 930 employees with sickness absence for three weeks or more. Work 2007, 29:233 238

39. D'Amato A, Zijlstra F: Toward a climate for work resumption: the nonmedical determinants of return to work. J Occup Environ Med 2010, $52: 6780$

40. Stuart H: Stigma and work. Healthcare Papers 2004, 5:100 111.

41. Vermeulen S, Anema J, Schellart A, van Mechelen W, van der Beek A: Intervention mapping for development of a participatory return-to-work intervention for temporary agency workers and unemployed workers sick-listed due to musculoskeletal disorders. BMC Public Health 2009, 9:1 15.

42. Lloyd J, Logan S, Greaves C, Wyatt K: Evidence, theory and context-using intervention mapping to develop a school-based intervention to prevent obesity in children. Int J Behav Nutr Phys Act 2011, 8:1 15.
43. Schmid A, Anderson J, Kent T, Williams L, Damush T: Using intervention mapping to develop and adapt a secondary stroke prevention program in Veterans Health Administration medical centers. Implement Sci 2010, 5:1 11.

44. Detaille S, van der Gulden J, Engels J, Heerkens Y, van Dijk F: Using intervention mapping (IM) to develop a self-management programme for employees with a chronic disease in the Netherlands. BMC Public Health 2010, 10:1 12.

45. Briand C, Durand MJ, St-Arnaud L, Corbiere M: Work and mental health: Learning from return-to-work rehabilitation programs designed for workers with musculoskeletal disorders. Int J Law Psychiatry 2007, 30:444 457.

46. Kok G, Bartholomew L, Parcel G, Gottlieb N, Fernandez M: Finding theory-and evidence-based alternatives to fear appeals: intervention mapping. Int J Psychol 2014, 49(2):98 107.

47. Oude Hengel K, Joling C, Proper K, van der Molen H, Bongers P: Intervention mapping as a framework for developing an intervention at the worksite for older construction workers. Am J Health Promot 2011, 26:e1 e10.

48. Kok G, Schaalma H, Ruiter R, Van Empelen P: Intervention mapping: a protocol for applying health psychology theory to prevention programmes. J Health Psychol 2004, 9:85 98.

49. de Vries H, Dijkstra M, Kuhlman P: Self-efficacy: the third factor besides attitude and subjective norm as a predictor of behavioural intentions. Health Educ Res 1988, 3:273 282.

50. Liska A: A critical examination of the causal structure of the Fishbein/ Ajzen attitude-behavior model. Soc Psychol Q 1984, 47:61 74.

51. Bandura A: Toward a unifying theory of behavioral change. Psychol Rev 1977, 84:101 215.

52. Polotajko H, Davis J, Stewart D, Cantin N, Amoroso B, Purdie L, Zimmerman D: Specifying the Domain of Concern: Occupation as Core. In Enabling Occupation II: Advancing an Occupational Therapy Vision for Health, Well-Being, \& Justice through Occupation. Edited by Townsend E, Polatajko H. Ottawa: CAOT Publications ACE; 2007:13 36.

53. Law M, Cooper B, Strong S, Stewart D, Rigby P, Letts L: The PersonEnvironment-Occupation Model: a transactive approach to occupational performance. Can J Occup Ther 1996, 63:9 23.

54. Petty R, Cacioppo J: The Elaboration Likelihood Model of Persuasion. In Communication and Persuasion. New York: Springer; 1986:1 24.

55. Petty R, Heesacker M, Hughes J: The elaboration likelihood model: implications for the practice of school psychology. J Sch Psychol 1997, 35:107 136

56. Rotter J: Generalized expectancies for internal versus external control of reinforcement. Psychol Monogr 1966, 80:1 27

57. Davidson L: Recovery in Serious Mental Illness: Paradigm Shift or Shibboleth. In Recovery from Severe Mental IIInesses: Research Evidence and Implications for Practice, Volume 1. Edited by L. D, Harding C, Spaniol L. Boston, Mass: Centre for Psychiatric Rehabilitation, Boston University; 2005:5 26.

58. Millward L, Lutte A, Purvis R: Depression and the perpetuation of an incapacitated identity as an inhibitor of return to work. J Psychiatr Ment Health Nurs 2005, 12:565 573

59. Kuhl J: A theory of self-regulation: action versus state orientation, selfdiscrimination, and some applications. Appl Psychol 1992, 41:97 129

60. Cole M, Tufano R: Applied Theories in Occupational Therapy: A Practical Approach. Slack Incorporated: Thorofare; 2008.

61. Katz N (Ed): Cognition, Occupation, and Participation Across the Life Span. 3rd edition. Bethesda: The American Occupational Therapy Association; 2011.

62. Gage M: The appraisal model of coping: an assessment and intervention model for occupational therapy. Am J Occup Ther 1992, 46:353 362.

63. Bandura A (Ed): Self-Efficacy in Changing Societies. Cambridge: Cambridge University Press; 1995.

64. Schaalma H, Kok G: Decoding health education interventions: the times are a-changin. Psychol Health 2009, 24:5 9.

65. Wang J: Mental Health Literacy and Stigma Associated With Depression in the Working Population. In Work Accommodation and Retention in Mental Health. Edited by Schultz IZ, Rogers ES. New York: Springer Science +Business Media; 2011:341 351

doi:10.1186/s12913-014-0530-4

Cite this article as: Wisenthal and Krupa: Using intervention mapping to deconstruct cognitive work hardening: a return-to-work intervention for people with depression. BMC Health Services Research 2014 14:530. 